\title{
Ratiometric Method for Rapid Monitoring of Biological Processes Using Bioresponsive MRI Contrast Agents
}

Serhat Gündüz, ${ }^{1,+}$ Tanja Savić, ${ }^{1,+}$ Rolf Pohmann, ${ }^{2}$ Nikos K. Logothetis, ${ }^{3,4}$ Klaus Scheffler ${ }^{2,5}$ and Goran Angelovski ${ }^{1, *}$

${ }^{1}$ MR Neuroimaging Agents, Max Planck Institute for Biological Cybernetics, Spemannstr. 41, 72076 Tübingen, Germany, E-mail: goran.angelovski@tuebingen.mpg.de

${ }^{2}$ High-Field Magnetic Resonance, Max Planck Institute for Biological Cybernetics, Tübingen, Germany.

${ }^{3}$ Physiology of Cognitive Processes, Max Planck Institute for Biological Cybernetics, Tübingen, Germany.

4 Department of Imaging Science and Biomedical Engineering, University of Manchester, Manchester, UK.

${ }^{5}$ Department for Biomedical Magnetic Resonance, University of Tübingen, Tübingen, Germany.

${ }^{\dagger}$ Contributed equally to this work.

\section{Table of Contents}

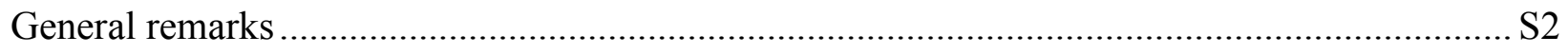

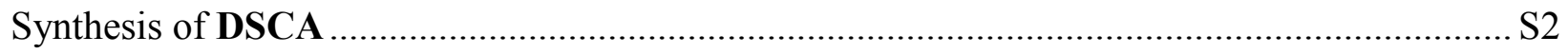

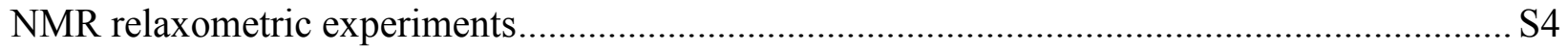

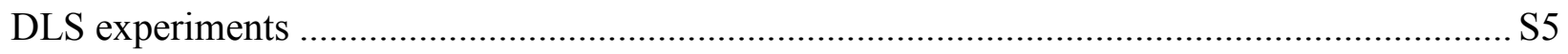

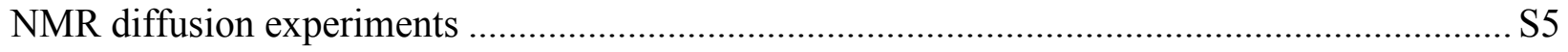

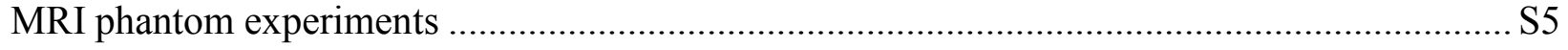

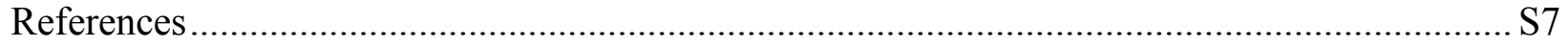




\section{General remarks}

Commercially available reagents and solvents were used without further purification. MSCA and isothiocyanate 1 for synthesis of dendrimeric DSCA were synthesized according to a published procedure. ${ }^{1}$ G4 Starburst $^{\circledR}$ PAMAM dendrimer with cystamine core was purchased from Dendritic Nanotechnologies, Inc., USA. Dendrimer $\mathbf{2}$ was purified using lipophilic Sephadex ${ }^{\circledR}$ LH-20 (bead size: 25-100 $\mu \mathrm{m}$ ) from Sigma-Aldrich (Germany). Brain extracellular model (BEM) solution was prepared from Ca-free Dulbecco's Modified Eagle's Medium (DMEM, without L-glutamine, sodium pyruvate and calcium chloride), Ham's F-12 Nutrient Mixture (F-12) and N-2 supplement (N-2) from Life Technologies GmbH, Germany. MALDITOF-MS analysis was performed by The Scripps Center for Mass Spectrometry, La Jolla, CA.

${ }^{1} \mathrm{H}$ and ${ }^{13} \mathrm{C}$ - NMR spectra, relaxometric experiments and NMR diffusion measurements were performed on a Bruker Avance III $300 \mathrm{MHz}$ spectrometer at $25^{\circ} \mathrm{C}$ using $5 \mathrm{~mm}$ NMR tubes. Processing was performed using TopSpin 2.1 (Bruker $\mathrm{GmbH}$ ) and $\mathrm{ACD} / \mathrm{SpecManager} 9.0$ (Advanced Chemistry Development, Inc.). The NMR spectra were obtained either in $\mathrm{CDCl}_{3}$ or $\mathrm{D}_{2} \mathrm{O}$, using the deuterium lock frequency. The concentration of $\mathrm{Gd}^{3+}$ in analyzed solutions was determined using the bulk magnetic susceptibility shift (BMS). ${ }^{2}$ Diffusion experiments were carried out on samples filtered through $0.20 \mu \mathrm{m}$ PTFE filters from Carl Roth $\mathrm{GmbH}+\mathrm{Co} . \mathrm{KG}$, Germany. DLS measurements were done on a Malvern-Nano-ZS (Zetasizer, software ver. 6.2) instrument. MRI measurements were performed on a Bruker BioSpec 70/30 USR magnet (software ver. Paravision 5.1) using Bruker dual frequency volume coil (RF RES 300 1H/19F 075/040 LIN/LIN TR).

\section{Synthesis of DSCA}

Dendrimer 2. G4 PAMAM dendrimer $(80 \mathrm{mg}, 5.6 \mu \mathrm{mol})$ and isothiocyanate $1(650 \mathrm{mg}, 539$ $\mu \mathrm{mol})$ were dissolved in dimethylformamide $(5 \mathrm{~mL})$ and triethylamine $(200 \mu \mathrm{L}, 1.4 \mathrm{mmol})$ was added to the solution. The reaction mixture was stirred at $45{ }^{\circ} \mathrm{C}$ for $24 \mathrm{~h}$. The solvent was evaporated and the unreacted ligand was removed using a lipophilic Sephadex column with methanol as eluent to obtain protected dendrimeric chelator 2 (270 mg, 53\%). 
${ }^{1} \mathrm{H}$ NMR (300 MHz, $\mathrm{CDCl}_{3}$ ): $\delta 7.2$ (br, $\left.\mathrm{ArH}\right), 7.04$ (br, $\mathrm{ArH}$ ), 4.10-1.70 (overlapping m), 1.551.25 (overlapping $\left.\mathrm{m}, \quad \mathrm{C}\left(\mathrm{CH}_{3}\right)_{3}\right)$. MALDI-TOF/MS $(\mathrm{m} / \mathrm{z}):[\mathrm{M}+44 \mathrm{Na}]^{2+}$ calcd. for $\mathrm{C}_{3024} \mathrm{H}_{5372} \mathrm{~N}_{610} \mathrm{Na}_{44} \mathrm{O}_{684} \mathrm{~S}_{42}{ }^{2+}, 31790$, found 31792 .

Dendrimer 3. The protected dendrimeric chelator $2(150 \mathrm{mg}, 2.9 \mu \mathrm{mol})$ was dissolved in formic acid $(5 \mathrm{~mL})$ and the mixture was stirred at $60{ }^{\circ} \mathrm{C}$ for $48 \mathrm{~h}$. The residue was purified by centrifugation using $3 \mathrm{KDa}$ molecular weight cut-off filters and freeze-dried to give dendrimeric chelator 3 as a light brown solid (135 mg, 90\%).

${ }^{1} \mathrm{H}$ NMR (300 MHz, $\mathrm{D}_{2} \mathrm{O}$ ): $\delta 7.24$ (br, ArH), 4.25-2.45 (overlapping m), 1.84 (br. s). MALDITOF/MS (m/z): $\left[\mathrm{M}+46 \mathrm{Na}+12 \mathrm{H}_{2} \mathrm{O}\right]^{2+}$ calcd. for $\mathrm{C}_{2224} \mathrm{H}_{3772} \mathrm{~N}_{610} \mathrm{Na}_{46} \mathrm{O}_{684} \mathrm{~S}_{42}\left(\mathrm{H}_{2} \mathrm{O}\right)_{12}{ }^{2+}, 26311$, found 26308 .

Dendrimer DSCA. Dendrimeric chelator $3(138 \mathrm{mg}, 2.4 \mu \mathrm{mol})$ was dissolved in water and the $\mathrm{pH}$ was adjusted to 7.0 with aqueous sodium hydroxide $(0.1 \mathrm{M})$. A solution of $\mathrm{GdCl}_{3} \cdot 6 \mathrm{H}_{2} \mathrm{O}(61$ $\mathrm{mg}, 164 \mu \mathrm{mol})$ in water was added and $\mathrm{pH}$ was maintained at 7.0. The mixture was stirred at room temperature for $24 \mathrm{~h}$. EDTA $(123 \mathrm{mg}, 329 \mu \mathrm{mol})$ was added into the solution to remove excess $\mathrm{Gd}^{3+}$ while maintaining $\mathrm{pH}$ at 7.0. Excess GdEDTA and EDTA were removed by centrifugation using $3 \mathrm{KDa}$ molecular weight cut-off filters and the resulting solution was lyophilized to give DSCA as a brown solid (151 mg, 85\%).

MALDI-TOF/MS $\quad(\mathrm{m} / \mathrm{z}): \quad\left[\mathrm{M}+53 \mathrm{Na}+78 \mathrm{H}_{2} \mathrm{O}\right]^{2+} \quad$ calcd. for $\mathrm{C}_{2224} \mathrm{H}_{3652} \mathrm{Gd}_{40} \mathrm{~N}_{610} \mathrm{Na}_{53} \mathrm{O}_{684} \mathrm{~S}_{42}\left(\mathrm{H}_{2} \mathrm{O}\right){ }_{78}{ }^{2+}$, 30070, found 30066; [M+36Na+43 $\left.\mathrm{H}_{2} \mathrm{O}\right]^{2+}$ calcd. for $\mathrm{C}_{2145} \mathrm{H}_{3534} \mathrm{Eu}_{38} \mathrm{~N}_{592} \mathrm{Na}_{36} \mathrm{O}_{656} \mathrm{~S}_{40}\left(\mathrm{H}_{2} \mathrm{O}\right)_{43}{ }^{2+}, 28386$, found 28385. 


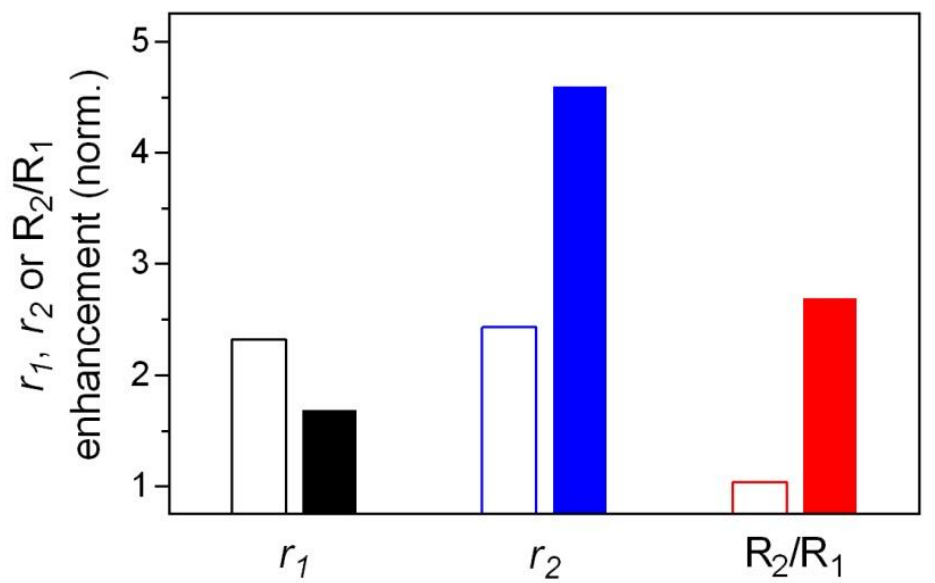

Figure S1. Increase of the $r_{1}, r_{2}$ and the $\mathrm{R}_{2} / \mathrm{R}_{1}$ ratio for MSCA (clear bars) and DSCA (colorfilled bars) upon saturation with $\mathrm{Ca}^{2+}$ (HEPES, $\mathrm{pH}$ 7.4). The plots show normalized values where the final $r_{1}, r_{2}$ or $\mathrm{R}_{2} / \mathrm{R}_{1}$ ratio value (at $\mathrm{Ca}^{2+}$ saturation) is divided by the initial value (in absence of $\left.\mathrm{Ca}^{2+}\right)$.

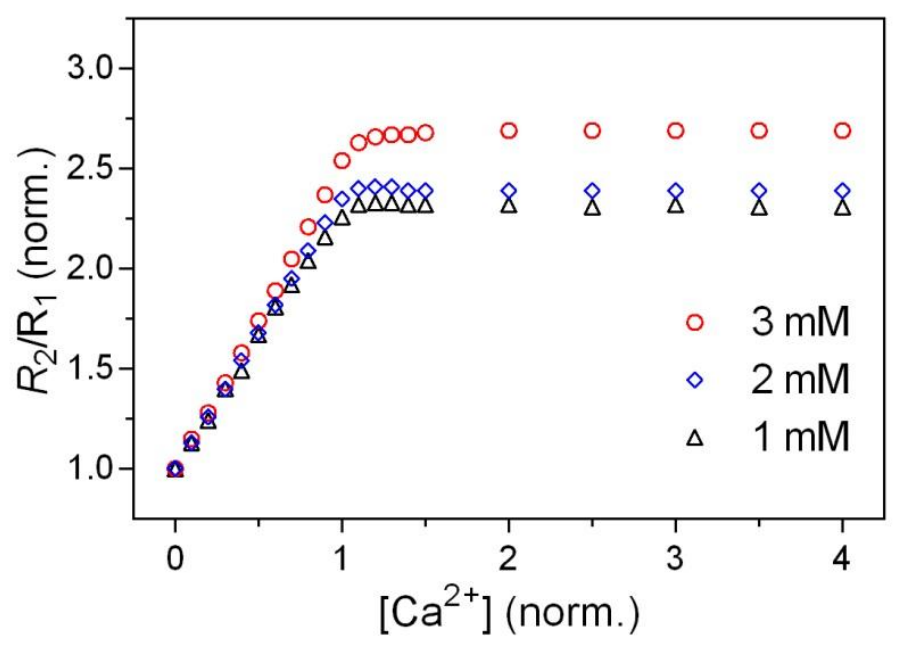

Figure S2. Longitudinal and transverse relaxometric titrations of DSCA with $\mathrm{Ca}^{2+}$ at $7 \mathrm{~T}$ and different $\mathrm{Gd}^{3+}$ concentrations ( $\mathrm{pH}$ 7.4, HEPES). The plots show normalized values where the final $r_{1}, r_{2}$ or $\mathrm{R}_{2} / \mathrm{R}_{1}$ ratio value (at $\mathrm{Ca}^{2+}$ saturation) is divided by the initial value (in absence of $\mathrm{Ca}^{2+}$. 


\section{DLS experiments}

Measurements were carried out with $\mathrm{Eu}^{3+}$ complex of DSCA $\left(0.75 \mathrm{mM} \mathrm{Eu}^{3+}\right)$ with and without addition of 2 equiv. of $\mathrm{Ca}^{2+}$. They included 5 repetitions of 15 scans $(1 \mathrm{scan}=12 \mathrm{sec}$, refractive index 1.345 , absorption $1 \%$ ), without delays in between the scans, and with equilibration of 30 sec prior to recording. For comparison with NMR diffusion experiments, the diffusion coefficient was calculated from the obtained diameter using the Stokes-Einstein equation (Eq. 1) and assuming spherical sample approximation, where $\mathrm{k}$ is the Boltzmann constant, $\mathrm{T}$ - absolute temperature $(298.15 \mathrm{~K}), \mathrm{r}$ - hydrodynamic radius of a sample, $\eta$ - viscosity of the water $(0.8872$ $\mathrm{mPa} \mathrm{s}$ ). The reversed procedure was performed for the diffusion coefficient obtained with NMR measurements of MSCA (see below).

$$
D=\frac{k T}{6 \pi r \eta}
$$

\section{NMR diffusion experiments}

Determination of diffusion coefficient was performed using 2D - Diffusion Ordered NMR Spectroscopy (DOSY). ${ }^{3}$ Experiments included 3 repetitions on $\mathrm{Eu}^{3+}$ complex of MSCA (15 mM) with and without 2 equiv. of $\mathrm{Ca}^{2+}(\delta \mathrm{t}=2 \mathrm{~ms}, \Delta \mathrm{T}=330 \mathrm{~ms})$. Data analysis was done with TopSpin 2.1 using 16 linear points between 5-95\% gradient strength.

\section{MRI phantom experiments}

MRI experiments were performed on tubes containing solutions of DSCA or MSCA (1 mM $\mathrm{Gd}^{3+}$ ) to which $0,0.4,0.8$ and 1.2 equiv. of $\mathrm{Ca}^{2+}$ were added (DSCA1=MSCA1 $=0 \mathrm{mM} \mathrm{Ca}{ }^{2+}$, DSCA2 $=$ MSCA2 $=0.4 \mathrm{mM} \mathrm{Ca}{ }^{2+}$, DSCA3=MSCA3 $=0.8 \mathrm{mM} \mathrm{Ca}^{2+}$, DSCA4=MSCA4=1.2 mM $\mathrm{Ca}^{2+}$ ). Each set (DSCA1-4 or MSCA1-4) was placed in $4 \times 200 \mu 1$ plastic tubes and inserted into a $20 \mathrm{~mL}$ syringe filled with solution of Dotarem $^{\circledR}$ in water $(162 \mathrm{mM})$ in order to avoid susceptibility artifacts.

Firstly, $T_{1}$ and $T_{2}$ times were determined from respective $T_{1}$ and $T_{2}$ maps using rapid acquisition with relaxation enhancement (RARE) with inversion recovery (IR-RARE) and multi-slice multi- 
echo (MSME) sequences, respectively. IR-RARE was performed with the following parameters: field-of-view $(\mathrm{FOV})=40 \times 40 \mathrm{~mm}^{2}$, matrix size $(\mathrm{MTX})=256 \times 256,1$ slice, slice thickness $1 \mathrm{~mm}$, echo time $(\mathrm{TE})=9.725 \mathrm{~ms}$, repetition time $(\mathrm{TR})=1500 \mathrm{~ms}$, Rare factor $=8$, inversion times $(\mathrm{TI})$ : $90,150,200,250,300,350,400,450,500,600,700,800,900,1000,1150,1300 \mathrm{~ms}$, number of averages $(\mathrm{NA})=1$, total acquisition time $(\mathrm{TA})=36 \mathrm{~s}$, while MSME with $\mathrm{FOV}=40 \times 40 \mathrm{~mm}^{2}$, MTX=128x128, 1 slice, slice thickness $1 \mathrm{~mm}$, TR=1500 ms, TE: 10, 15, 20, 25, 30, 35, 40, 45, $50,55,60,70,80,90,100,135,170,200 \mathrm{~ms} ; \mathrm{NA}=1, \mathrm{TA}=3 \mathrm{~min} 12 \mathrm{~s}$. Obtained $\mathrm{T}_{1}$ and $\mathrm{T}_{2}$ times were further employed for numerical CNR optimization of acquisition parameters for $T_{1^{-}}, T_{2^{-}}$and $\mathrm{T}_{2} / \mathrm{T}_{1}$-weighted imaging. Numerical CNR optimization for FLASH, bSSFP and RARE was based on Bloch simulations that optimize the signal difference for different contrast agents. The resulting optimized TR and flip angle were then used for measurements and the signal difference was normalized with the square root of the total measuring time. ${ }^{4}$

MRI was accomplished using $T_{1^{-}}, T_{2^{-}}$and $T_{2} / T_{1}$-weighted sequences: fast low angle shot (FLASH), RARE and balanced steady state free precession (bSSFP) pulse sequence, respectively, with FOV $=25 \times 25 \mathrm{~mm}^{2}$, MTX $=256 \times 256,1$ slice and slice thickness $1 \mathrm{~mm}$.

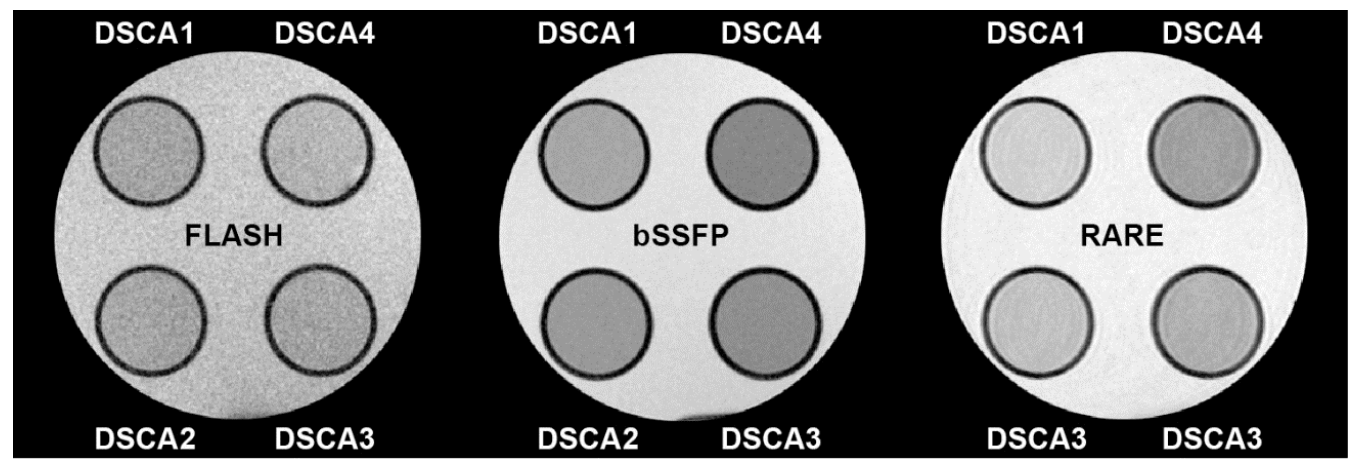

Figure S3. Comparison of MRI sequences with DSCA at different $\mathrm{Ca}^{2+}$ concentrations $\left(\left[\mathrm{Gd}^{3+}\right]=\right.$ $1 \mathrm{mM}, 7 \mathrm{~T}, \mathrm{pH}$ 7.4, HEPES). Parameters for FLASH: TR/TE= 3.797/1.494 ms, FA= 19, NA=16, $\mathrm{TA}=15.552 \mathrm{~s}$, for $\mathrm{bSSFP}: \mathrm{TR} / \mathrm{TE}=3 / 1.5 \mathrm{~ms}, \mathrm{FA}=81, \mathrm{NA}=16, \mathrm{TA}=12.288 \mathrm{~s}$, and for RARE:

$\mathrm{TR} / \mathrm{TE}=620 / 9.284 \mathrm{~ms}$, Rare factor $=16, \mathrm{NA}=16, \mathrm{TA}=2 \mathrm{~m} 38 \mathrm{~s} 720 \mathrm{~ms}$. 


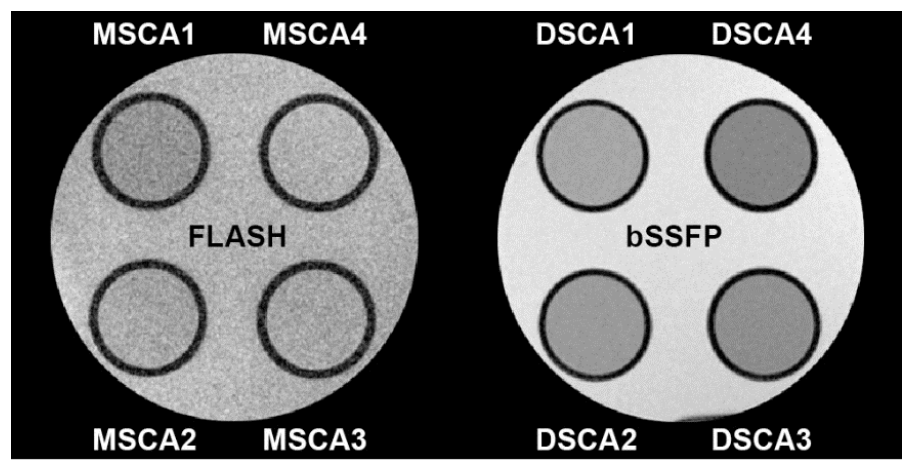

Figure S4. Comparison of FLASH sequence with MSCA and bSSFP sequence with DSCA at different $\mathrm{Ca}^{2+}$ concentrations $\left(\left[\mathrm{Gd}^{3+}\right]=1 \mathrm{mM}, 7 \mathrm{~T}, \mathrm{pH}\right.$ 7.4, HEPES). Parameters for FLASH: $\mathrm{TR} / \mathrm{TE}=3.4 / 1.494 \mathrm{~ms}, \mathrm{FA}=21, \mathrm{NA}=16, \mathrm{TA}=13.926 \mathrm{~s}$, and for $\mathrm{bSSFP}: \mathrm{TR} / \mathrm{TE}=3 / 1.5 \mathrm{~ms}$, $\mathrm{FA}=81, \mathrm{NA}=16, \mathrm{TA}=12.288 \mathrm{~s}$.

Table S1. SNR values obtained for DSCA and MSCA in the presence or absence of 1.2 equiv. of $\mathrm{Ca}^{2+}$, using $\mathrm{T}_{1^{-}}, \mathrm{T}_{2-}$ and $\mathrm{T}_{2} / \mathrm{T}_{1}$-weighted sequences.

\begin{tabular}{|c|c|c|c|c|c|c|}
\hline \multirow{2}{*}{$\begin{array}{c}\text { Contrast } \\
\text { agent }\end{array}$} & \multicolumn{2}{|c|}{$\begin{array}{c}\text { T}_{1} \text {-weighted } \\
\text { (FLASH) }\end{array}$} & \multicolumn{2}{c|}{$\begin{array}{c}\text { T2-weighted } \\
\text { (RARE) }\end{array}$} & \multicolumn{2}{|c|}{$\begin{array}{c}\mathbf{T}_{2} / \mathbf{T}_{1} \text {-weighted } \\
\text { (bSSF) }\end{array}$} \\
\cline { 2 - 7 } & $\mathrm{No} \mathrm{Ca}^{2+}$ & $\begin{array}{c}+\mathrm{Ca}^{2+} \\
(1.2 \text { equiv. })\end{array}$ & $\mathrm{No} \mathrm{Ca}^{2+}$ & $\begin{array}{c}+\mathrm{Ca}^{2+} \\
(1.2 \text { equiv. })\end{array}$ & $\mathrm{No} \mathrm{Ca}^{2+}$ & $\begin{array}{c}+\mathrm{Ca}^{2+} \\
(1.2 \text { equiv. })\end{array}$ \\
\hline DSCA & 5.41 & 6.27 & 11.83 & 8.50 & 9.75 & 7.39 \\
\hline MSCA & 4.81 & 6.12 & 13.44 & 12.60 & 10.41 & 10.95 \\
\hline
\end{tabular}

a) DSCA: TA=3888 ms, MSCA: TA=3481 ms; b) DSCA: TA=9920 ms, MSCA: $\mathrm{TA}=14400 \mathrm{~ms} ; \mathrm{c}) \mathrm{TA}=767.5 \mathrm{~ms}$.

\section{References}

1. Gündüz, S.; Nitta, N.; Vibhute, S.; Shibata, S.; Maier, M. E.; Logothetis, N. K.; Aoki, I.; Angelovski, G., Dendrimeric calcium-responsive MRI contrast agents with slow in vivo diffusion. Chem. Commun. 2015, 51, 2782-2785.

2. Corsi, D. M.; Platas-Iglesias, C.; van Bekkum, H.; Peters, J. A., Determination of paramagnetic lanthanide(III) concentrations from bulk magnetic susceptibility shifts in NMR spectra. Magn. Reson. Chem. 2001, 39, 723-726.

3. Macchioni, A.; Ciancaleoni, G.; Zuccaccia, C.; Zuccaccia, D., Determining accurate molecular sizes in solution through NMR diffusion spectroscopy. Chem. Soc. Rev. 2008, 37, 479-489.

4. Hagberg, G. E.; Scheffler, K., Effect of $r_{1}$ and $r_{2}$ relaxivity of gadolinium-based contrast agents on the $T_{1}$-weighted MR signal at increasing magnetic field strengths. Contrast Media Mol. Imaging 2013, $8,456-465$. 